\title{
PENGAJARAN MATEMATIK SEKOLAH RENDAH MENGGUNAKAN PENDEKATAN KONTEKSTUAL : SATU KAJIAN KES
}

\author{
${ }^{1}$ Norsyaidah Seliaman, ${ }^{2}$ Mohd Uzi Dollah \\ ${ }^{1,2}$ Fakulti Pembangunan Manusia, Universiti Pendidikan Sultan Idris \\ 35900 Tanjong Malim, Perak Darul Ridzuan \\ *emel : uzi.dollah@fpm.upsi.edu.my
}

Received : 10 Julai 2018; Accepted : 28 Ogos 2018; Published : 27 Disember 2018

\begin{abstract}
Abstrak
Kajian ini bertujuan bagi mendalami dan meneroka pengajaran matematik sekolah rendah menggunakan pendekatan kontekstual berdasarkan lapan komponen teori Johnson (2002). Terdapat tiga objektif kajian iaitu pemahaman guru matematik mengenai pendekatan kontekstual, pelaksanaan pengajaran kontekstual yang digunakan oleh guru matematik dan halangan yang dihadapi oleh guru matematik dalam proses pengajaran dan pembelajaran (PdPc). Reka bentuk kajian kes secara kualitatif dengan menggunakan penelitian kajian secara naturalistik telah dilaksanakan bagi mengamati sebuah latar tertentu tanpa sedikit pun mengubahnya di mana, persampelan adalah purposif. Kajian ini melibatkan 4 orang guru matematik daripada dua buah sekolah rendah daripada populasi 107 buah sekolah dalam Daerah Seremban, Negeri Sembilan. Kajian ini melibatkan empat kaedah pengumpulan data iaitu temu bual pra dan pasca- pengajaran, pemerhatian, nota lapangan (senarai semak) dan pengumpulan dokumen. Hasil kajian menunjukkan bahawa semua peserta kajian menghadapi kesukaran dan kurang pasti dalam menjelaskan makna pendekatan kontekstual, namun peserta kajian lebih berkeyakinan setelah menerima penerangan secara umum daripada penyelidik serta sebahagian besar peserta kajian berupaya melaksanakannya dalam proses PdP. Dapatan kajian juga menunjukkan peserta kedua dan ketiga berupaya melaksanakan pendekatan kontekstual dalam kedua-dua sesi, peserta keempat berupaya melaksanakannya pada sesi kedua berbanding sesi pertama, manakala peserta pertama tidak berupaya laksanakannya pada kedua-dua sesi pemerhatian pengajaran. Kesimpulan daripada kajian, penggunaan pendekatan kontekstual dalam pengajaran matematik sekolah rendah bergantung pada kefahaman dan pengetahuan guru tentang strategi pengajaran kontekstual secara mendalam dan berkesan. Implikasi kajian menunjukkan, pengajaran secara kontekstual menjadikan PdP guru bersama murid lebih bermakna dan efektif dengan mengaitkan Matematik dengan situasi sebenar dan kehidupan seharian.
\end{abstract}

\section{Kata kunci Pendekatan Kontekstual, Pengajaran Matematik Sekolah} Rendah. 


\begin{abstract}
The aim of this study were to deepen and explore for teaching elementary school mathematics by using contextual approach based on the eight components theory of Johnson (2002). There were three objectives of the study of mathematics teachers' understanding of the contextual approach, implementation of contextual teaching mathematics used by teachers in the teaching and learning (T\&L) process and obstacles faced by teachers in the process of T\&L. The qualitative case studies using naturalistic research study was conducted to observe itself for a certain background without the slightest change, the samples were purposive sampling. The study involved 4 mathematics teacher of two primary schools out of a population of 107 schools in Seremban, Negeri Sembilan. This study is to involve four methods of data collection interviews pre- and post-lesson, observations, field notes (checklist) and collecting documents. The study results showed that all study participants facing difficulty in explaining exactly meaning of contextual approach, but participants more confident to explain and shows their teaching skills in class session after receiving description in general by the researchers. Findings of research also showed second and third participant successfully implemented contextual approach in both sessions, the fourth participant have successfully implemented second session compared to the first session, but the first participant did not manage to implement it in both sessions of teaching observation. The conclusion of the study, successfully of using contextual approach in teaching elementary school mathematics depends on understanding and knowledge of teachers about teaching strategies in-depth. Implications of research shows, teaching contextually make T\&L teachers with students more meaningful and effective, with associate mathematics to the real situation and everyday life.
\end{abstract}

Keywords Contextual Approach, Teaching Primary School Mathematics.

\title{
PENDAHULUAN
}

Arus perkembangan semasa menuntut kepada perubahan dari segenap aspek mahupun lapangan kehidupan umum. Perubahan positif merupakan anjakan yang perlu dihasilkan bagi mewujudkan kedinamikan untuk menghadapi cabaran-cabaran baru seiring perkembangan semasa. Justeru, pendidikan masa kini perlu kepada pembaharuan bagi merealisasikan proses pembentukan dan pengembangan potensi diri yang patut disalurkan kepada para pelajar. Bagi tujuan tersebut penelitian terhadap aspek pengajaran khususnya dalam bilik darjah menjadi asas pencapaian kecemerlangan akademik buat para pelajar. Hal ini melibatkan kemahiran serta penguasaan penuh guru terhadap pelajaran yang disampaikan.

Menurut Modul Pembelajaran Kontekstual (2003) yang dilaksanakan oleh Pusat Perkembangan Kurikulum Kementerian Pendidikan Malaysia untuk para guru di 
Malaysia, menyatakan bahawa pembelajaran hanya akan berlaku apabila murid dapat memproses maklumat atau pengetahuan baru dengan cara yang bermakna kepada mereka. Minda seseorang akan cuba mencari makna dalam konteks dengan membuat hubung kait yang bermakna dan relevan dengan persekitarannya.

Strategi pengajaran yang berkesan mungkin bermula dengan pengajaran berpusatkan murid. Dengan menjalankan pelbagai aktiviti, akan menjadikan pembelajaran lebih menarik dan bermakna. Selain menyampaikan kandungan subjek dengan pendekatan tradisional, adalah disyorkan supaya muridmurid lebih terlibat secara aktif dalam proses pembelajaran. Pengajaran juga perlu berkaitan dengan situasi kehidupan sebenar.

Matlamat pendidikan hari ini yang ditekankan dalam Kurikulum Standard Sekolah Rendah (KSSR), menyarankan guru agar menggalakkan murid untuk terlibat dalam proses PdP guru. Selain itu, ianya juga bertujuan bagi menarik minat murid untuk fokus, aktif dan memberikan keseronokan kepada murid dalam menjalankan proses pembelajaran harian bersama guru. Sudah tentu teknik pembelajaran berpusatkan murid lebih berkesan ke arah mencapai matlamat pendidikan matematik itu sendiri.

\section{TUJUAN KAJIAN}

Kajian ini bertujuan untuk bagi mendalami dan meneroka pengajaran matematik sekolah rendah menggunakan pendekatan kontekstual berdasarkan lapan komponen teori Johnson (2002). Objektif kajian ini adalah untuk :

i. Untuk mengkaji pemahaman guru matematik mengenai pendekatan kontekstual.

ii. Untuk mengkaji perlaksanaan pengajaran kontekstual yang digunakan oleh guru matematik dalam proses PdPc.

iii. Untuk mengkaji halangan yang dihadapi oleh guru matematik dalam proses PdPc semasa melaksanakan pendekatan kontekstual.

\section{METODOLOGI KAJIAN}

Reka bentuk kajian kes secara kualitatif dengan menggunakan penelitian kajian secara naturalistik dilaksanakan oleh penyelidik bagi mengamati sendiri sebuah latar tertentu tanpa sedikit pun mengubahnya di mana, persampelan adalah purposif dan sampel tidak banyak yang dipilih berdasarkan tujuan penyelidikan. Kajian ini melibatkan 4 orang guru matematik daripada dua buah sekolah rendah daripada populasi 107 buah sekolah dalam Daerah Seremban, Negeri Sembilan. Walaupun, jumlah peserta kajian adalah hanya 4 orang sahaja, berdasarkan prosedur kajian ini setiap seorang peserta kajian perlu melibatkan diri sebanyak dua kali sesi pemerhatian pengajaran oleh penyelidik. Kajian ini melibatkan empat kaedah pengumpulan data iaitu temu bual pra dan pascapengajaran, pemerhatian, nota lapangan (senarai semak) dan pengumpulan dokumen. 


\section{DAPATAN KAJIAN}

Dapatan kajian menunjukkan :

Jadual 1 Pemahaman Guru Matematik Mengenai Pendekatan Kontekstual

\begin{tabular}{|c|c|c|c|}
\hline PESERTA 1 & PESERTA 2 & PESERTA 3 & PESERTA 4 \\
\hline $\begin{array}{l}\text { PERMULAAN } \\
\text { (sebelum penerangan } \\
\text { umum daripada } \\
\text { penyelidik) }\end{array}$ & $\begin{array}{l}\text { PERMULAAN } \\
\text { (sebelum penerangan } \\
\text { umum daripada } \\
\text { penyelidik) }\end{array}$ & $\begin{array}{l}\text { PERMULAAN } \\
\text { (sebelum penerangan } \\
\text { umum daripada } \\
\text { penyelidik) }\end{array}$ & $\begin{array}{l}\text { PERMULAAN } \\
\text { (sebelum } \\
\text { penerangan } \\
\text { umum daripada } \\
\text { penyelidik) }\end{array}$ \\
\hline $\begin{array}{l}\text { - Kurang pasti makna } \\
\text { sebenar pendekatan } \\
\text { kontekstual }\end{array}$ & $\begin{array}{l}\text { - Kurang pasti makna } \\
\text { sebenar pendekatan } \\
\text { kontekstual }\end{array}$ & $\begin{array}{l}\text { - Kurang pasti } \\
\text { makna sebenar } \\
\text { pendekatan } \\
\text { kontekstual }\end{array}$ & $\begin{array}{l}\text { - Kurang pasti } \\
\text { makna sebenar } \\
\text { pendekatan } \\
\text { kontekstual }\end{array}$ \\
\hline $\begin{array}{l}\text { SESI TEMUBUAL } \\
\text { (Pra \& pasca- } \\
\text { pengajaran) } \\
\text { - Lebih yakin } \\
\text { menjelaskan } \\
\text { makna pendekatan } \\
\text { kontekstual } \\
\text { - Beserta contoh }\end{array}$ & $\begin{array}{l}\text { SESI TEMUBUAL } \\
\text { (Pra \& pasca- } \\
\text { pengajaran) } \\
\text { - Lebih yakin } \\
\text { menjelaskan } \\
\text { makna pendekatan } \\
\text { kontekstual } \\
\text { - Beserta contoh }\end{array}$ & $\begin{array}{l}\text { SESI TEMUBUAL } \\
\text { (Pra \& pasca- } \\
\text { pengajaran) } \\
\text { - Lebih yakin } \\
\text { menjelaskan } \\
\text { makna pendekatan } \\
\text { kontekstual } \\
\text { - Beserta contoh }\end{array}$ & $\begin{array}{l}\text { SESI } \\
\text { TEMUBUAL } \\
\text { (Pra \& pasca- } \\
\text { pengajaran) } \\
\text { - Lebih yakin } \\
\text { menjelaskan } \\
\text { makna pendekatan } \\
\text { kontekstual } \\
\text { - Beserta contoh }\end{array}$ \\
\hline $\begin{array}{l}\text { PEMERHATIAN } \\
\text { - Tidak membuat } \\
\text { hubungan bermakna } \\
\text { (HB) [SESI I \& II] }\end{array}$ & $\begin{array}{l}\text { PEMERHATIAN } \\
\text { - Membuat hubungan } \\
\text { bermakna (HB) } \\
\text { [SESI I \& II] }\end{array}$ & $\begin{array}{l}\text { PEMERHATIAN } \\
\text { - Membuat } \\
\text { hubungan bermakna } \\
\text { (HB) [SESI I \& II] }\end{array}$ & $\begin{array}{l}\text { PEMERHATIAN } \\
\text { - Membuat } \\
\text { hubungan } \\
\text { bermakna (HB) } \\
\text { [SESI II sahaja] }\end{array}$ \\
\hline
\end{tabular}

Berdasarkan Jadual 1 menunjukkan bahawa, pemahaman guru matematik tentang pendekatan kontekstual. Pada permulaan, kebanyakan peserta kajian menyatakan mereka kurang pasti tentang makna bagi pendekatan kontekstual sebelum sesi temu bual diadakan. Walau bagaimanapun, setelah peserta kajian menerima penerangan secara umum daripada penyelidik, semua peserta kajian lebih yakin dan berupaya menjelaskan kefahaman mereka tentang pendekatan kontestual dengan beserta contoh sekali.

Walaupun, peserta kajian dapat menjelaskan tentang pendekatan kontekstual dalam sesi temu bual, namun bagi membuktikan kefahaman mereka tentang pendekatan kontekstual, peserta kajian perlu mengaplikasikannya dalam PdPc di dalam bilik darjah bersama murid. Hal ini bermakna penyataan peserta kajian dalam sesi temu bual perlulah seiring dengan pelaksanaannya dalam PdP. Berdasarkan dua sesi pemerhatian bersama penyelidik, beberapa orang peserta kajian dapat 
mengaplikasikan kefahaman mereka tentang pendekatan kontekstual dengan membuat hubungan bermakna (HB) dalam kedua-dua sesi pemerhatian. Ada peserta kajian juga berjaya mengaplikasikannya pada sesi kedua sahaja, serta ada juga peserta kajian yang tidak melaksanakannya dalam kedua-dua sesi pemerhatian.

Jadual 2 Pelaksanaan Pengajaran Kontekstual Yang Digunakan Oleh Guru Dalam Proses PdPc.

\begin{tabular}{|l|l|l|l|}
\hline \multicolumn{1}{|c|}{ PESERTA 1 } & \multicolumn{1}{c|}{ PESERTA 2 } & PESERTA 3 & \multicolumn{1}{c|}{ PESERTA 4 } \\
\hline SESI I \& II & \multicolumn{1}{c|}{ SESI I \& II } & SESI I \& II & \multicolumn{1}{c|}{ SESI I } \\
- Penerangan & - Penerangan & - Penerangan/ & - Penerangan \\
- Kad nombor (flash & - Contoh benda wujud & komunikasi & - Kad nombor \\
card) dilekatkan di & dalam bilik darjah/ & - Demonstrasi & \\
papan hitam & milik murid & - Aktiviti contoh & SESI II \\
- Kaedah pengiraan & - Simulasi/ & bahan milik & - Perkaitan \\
jari & demonstrasi & murid & kehidupan seharian \\
& - Contoh situasi & - Contoh benda & - Contoh benda \\
& harian/ sebenar. & dalam bilik & wujud dalam bilik \\
& & darjah/luar bilik & darjah \\
& & darjah & - Demonstrasi/ \\
& & - Pelekat/gambar & simulasi \\
& & di dinding & \\
& & (kepelbagaian & \\
& & bentuk secara & \\
& & realiti) & \\
\hline
\end{tabular}

Berdasarkan Jadual 2 menunjukkan bahawa, pelaksanaan pengajaran kontekstual yang digunakan oleh guru dalam proses PdPc. Beberapa peserta kajian didapati berupaya melaksanakan pendekatan kontekstual dengan membuat hubungan bermakna (HB) melalui mengaitkan PdPc tentang kehidupan seharian dan situasi sebenar dalam kedua-dua sesi pemerhatian.

Walau bagaimanapun, terdapat juga peserta tidak melaksanakan PdPc dengan membuat hubungan bermakna (HB) dalam kedua-dua sesi pemerhatian serta ada juga peserta juga memperbaiki mutu pengajaran dengan melaksanakan pendekatan kontekstual melalui membuat hubungan bermakna (HB) pada sesi kedua berbanding sesi pertama.

Perbezaan antara peserta kajian dapat dilihat melalui kaedah pengajaran, dimana ada peserta kajian lebih selesa menggunakan kaedah penerangan sahaja tanpa mengaitkan PdPc dengan kehidupan seharian atau situasi sebenar. Manakala, bagi peserta kajian yang melaksanakan pendekatan kontekstual, mereka berupaya mengaitkan PdPc dengan kehidupan seharian seperti memberi contoh-contoh benda atau bahan yang wujud dalam bilik darjah dan sekeliling murid serta memberikan situasi sebenar sebagai membantu PdPc lebih mudah difahami dan menyeronokkan. 
Jadual 3 Halangan Sepanjang Proses Pengajaran Peserta Kajian

\begin{tabular}{|c|c|c|c|}
\hline PESERTA 1 & PESERTA 2 & PESERTA 3 & PESERTA 4 \\
\hline $\begin{array}{c}\text { - Masalah Literasi } \\
\text { dan Numerasi }\end{array}$ & $\begin{array}{c}\text { - Kebisingan murid } \\
\text { yang keterlaluan }\end{array}$ & $\begin{array}{c}\text { - Ada murid hilang } \\
\text { tumpuan dan bising }\end{array}$ & $\begin{array}{l}\text { - Lemah Literasi dan } \\
\text { Numerasi }\end{array}$ \\
$\begin{array}{c}\text { - Penguasaan murid } \\
\text { yang lemah (murid } \\
\text { yang sama). }\end{array}$ & $\begin{array}{c}\text { - Wujud murid pasif } \\
\text { enggan ikut serta } \\
\text { dalam PdPc guru }\end{array}$ & $\begin{array}{c}\text { - Ada murid } \\
\text { mengganggu murid } \\
\text { lain untuk fokus }\end{array}$ & $\begin{array}{l}\text { - Murid sukar } \\
\text { dikawal bila } \\
\text { terlalu aktif atau } \\
\text { teruja }\end{array}$ \\
\hline
\end{tabular}

Berdasarkan Jadual 4.5 menunjukkan bahawa, halangan sepanjang proses pengajaran peserta kajian. Berdasarkan sesi temu bual pasca-pengajaran, peserta kajian menyatakan halangan atau masalah yang mereka hadapi sepanjang proses pengajaran dijalankan.

Menurut sesi temu bual tersebut, kebanyakan peserta kajian mengalami masalah kebisingan murid yang keterlaluan dalam bilik darjah terutama apabila murid terlalu teruja menjalankan aktiviti secara berkumpulan atau aktiviti yang menggunakan bahan-bahan tertentu seperti pensil warna dan sebagainya. Masalah ini menjadi masalah utama yang dihadapi oleh peserta kajian kedua dan ketiga, manakala bagi peserta pertama dan keempat, kedua-duanya menghadapi halangan utama dalam PdPc seperti murid mempunyai masalah literasi dan numerasi.

Halangan atau masalah lain yang dihadapi oleh peserta kajian ialah masalah murid lemah dalam penguasaan di mana daripada murid yang sama (peserta pertama), murid pasif tidak mahu mengikuti PdPc guru (peserta kedua), murid tidak fokus dan mengganggu rakan lain (peserta ketiga) dan murid sukar dikawal apabila terlalu aktif (peserta keempat). Walaupun, peserta kajian mengalami halangan atau masalah ini dalam proses PdPc, namun para peserta kajian berupaya mengawal keadaan murid hingga selesai proses PdPc dijalankan.

\section{KESIMPULAN DAN PERBINCANGAN}

Dapatan kajian menunjukkan beberapa peserta kajian berupaya melaksanakan pengajaran secara kontekstual dengan baik dan berkesan, manakala sebahagian peserta kajian lain pula perlu memperbaiki mutu pengajaran supaya teknik dan strategi pengajaran dengan menggunakan pendekatan kontekstual dapat diperbaiki dan dipertingkatkan.

Definisi dan matlamat sebenar pendekatan kontekstual adalah kandungan pengajaran dan pembelajaran yang menghubungkaitkan kehidupan seharian dan situasi sebenar secara bermakna (Johnson 2002). Dengan itu, guru perlu mengaitkan pengajaran dan topik pembelajaran secara relevan yang mempunyai hubungan bermakna dengan persekitaran murid yang merupakan pengetahuan sedia ada dan pengalaman bagi mereka sebelum ini (Dale Parnell, 2001) seperti benda yang wujud dalam bilik darjah, luar bilik darjah, persekitaran sekolah, di rumah, situasi harian yang sering berlaku disekeliling murid dan sebagainya. 
Walaupun sepanjang proses PdPc peserta kajian mempunyai beberapa masalah dan halangan, namun peserta kajian dapat mengawal keadaan murid dan bilik darjah dengan baik serta masalah berkenaan juga dapat diatasi, seterusnya kelancaran proses PdPc dapat diteruskan hingga tamat waktu PdPc. Kajian yang telah dilaksanakan ini yang berteraskan pendekatan kontekstual bukan sahaja memberikan kebaikan pada pembelajaran murid-murid tetapi menjadi fokus utama kepada para peserta kajian supaya mereka dapat kenalpasti sejauh mana keberkesanan dan mutu pengajaran secara kontekstual berbanding pengajaran yang sebelumnya.

\section{RUJUKAN}

Aini Hayati, P. @ F., (2012). Standard Pengajaran Matematik Dalam Kalangan Guru Matematik Sekolah Rendah. Tesis bagi memenuhi keperluan Ijazah Sarjana Pendidikan, UPSI, tidak diterbitkan.

Baker, E. D., Hope, L., and Karandjeff. K. (2009). Contextualized Teaching \& Learning: A Faculty Primer A Review of Literature and Faculty Practices with Implications for California Community College Practitioners. Retrieved on September 5, 2015 from http://www.cccbsi.org/Websites/basicskills/Images/CTL.pdf

Berns, R., \& Erickson, P. (2001). An Interactive Web-based Model for the Professional Development of Teachers in Contextual Teaching and Learning. Bowling Green State University. Retrieved from http://www.bgsu.edu/ctl.

Berns, R. G. \& Erickson, P. M. (2001). “Contextual Teaching and Learning: Preparing Students for the New Economy “, The Highlight Zone: Research @ Work No. 5 , 2001. Retrieved January 9, 2015 from: http:/www.nccte.org/publications/ infosynthesis/highlight zone/highlight05/highlight05-CTL.pdf

Bishop, A. J. (2000). Overcoming obstacles to the democratisation of mathematics education. Regular lecture presented at the Ninth International Congress on Mathematics Education, Mauhari, Japan. Retrieved on September 5, 2015, from http://www.education. Monash.edu.au/projects/vamp/mav98.html.

Bond, L. P. (2004). Using contextual instruction to make abstract learning concrete. ACTE: Techniques. Retrieved from http://acteonline.org Chernus, K., \& Fowler, D. (2009). Integrating curriculum: Lessons for adult education from career and technical education. National Institute for Literacy, Technical Assistance for Program Planning.

Faiq, D. (2009). Penelitian tindakan kelas. Metode Penelitian Naturalistik Kualitatif. Retrieved 19 November 2016 from penelitiantindakankelas.blogspot.mu/2009/03/ metode-penelitian-naturalistikkualitati.html.

Johnson, E. B. (2002). Contextual Teaching and Learning: What it is and Why it's here to stay. Thousands Oaks, California: Corwin Press, Inc. ISBN 0-7619-7864-X

Komalasari, K. (2009). The effect of contextual Learning in civic education on students' civi competence. Journal of Social Sciences, 5(4), 261-270. Retrieved from http:// www.scipub.org/fulltext/jss/jss54261-270.pdf

Lynch, R. L., \& Harnish, D. (2003). Implementing contextual teaching and learning by novice teachers. Final report. (Contract\# ED-98-CO-0085, 1998-2003). Retrieved from http://www.coe.uga.edu/ctl/casestudy/Final.pdf 
Mohamad Johdi, H. S. (2007). Guru Efektif dan Peranan Guru dalam Mencapai Objektif Persekolahan Sekolah Rendah : Perspektif Guru Besar : Seminar Penyelidikan Pendidikan Institut Perguruan Batu Lintang. Retrieved 13 December 2016 from http://cikgumadrid.blogspot.my/2011/09/kerja-kursus-pendek-muriddan-alam.html

Mohd Uzi, D., Noor Shah, S., \& Mohd Faizal, N. L. A. (2014). Nilai Matematik dalam Pengajaran Matematik PJJ Sekolah Rendah. Kod Penyelidikan : 2012-0136-10701. Universiti Pendidikan Idris.

Mohd Uzi, D. (2006). Pengajaran dan Pembelajaran Matematik melalui Penyelesaian Masalah. Dewan Bahasa dan Pustaka Kuala Lumpur, Dewan Bahasa dan Pustaka. Murni (2013). Pengajaran Matematik Dengan Pendekatan Pengajaran Mengikut Konteks Di Sekolah Vocational : Suatu Kajian Kes. Kajian Penyelidikan Program Doktor Falsafah Pendidikan Matematik Fakuti Sains dan Teknologi, Universiti Pendidikan Sultan Idris, tidak diterbitkan.

Nurhadi (2002). Pendekatan Kontekstual (Contextual Teaching and Learning (CTL). Malang: Universitas Negeri Malang (UM).pres.

Othman, L. (2014). Penyelidikan Kualitatif: Pengenalan Kepada Teori Dan Metode. Penerbitan Universiti Pendidikan Sultan Idris (UPSI), ISBN: 983-2620-81-3.

Predmore, S. R. (2005). Putting it into context. Techniques. Retrieved January 9, 2015, from http://www. acteonline.org.

Schell, J. W. (2001). An emerging framework for contextual teaching and learning in preservice teacher education. Retrieved from http://www.coe.uga.edu/ctl/theory/ framework.pdf 